\title{
Noise Analysis of Trans-impedance Amplifier (TIA) in Variety Op Amp for use in Visible Light Communication (VLC) System
}

\author{
Syifaul Fuada ${ }^{1}$, Angga Pratama Putra ${ }^{2}$, Yulian Aska ${ }^{3}$, Trio Adiono ${ }^{4}$ \\ ${ }^{1,2}$ Electrical Engineering, School of Electrical Engineering and Informatics (SEEI), Institut Teknologi Bandung, \\ Indonesia \\ ${ }^{3,4}$ University Center of Excellence on Microelectronics, Institut Teknologi Bandung, Indonesia
}

\begin{tabular}{l} 
Article Info \\
\hline Article history: \\
Received Jun 19, 2017 \\
Revised Oct 20, 2017 \\
Accepted Dec 4, 2017 \\
\hline
\end{tabular}

Keyword:

Noise

Op amp

Photodiode

Transimpedance amplifier

Visible light communication

\begin{abstract}
VLC is a complex system with lots of challenges in its implementation. One of its problems is noise that originated from internal and external sources (sunlight, artificial light, etc). Internal noise is originated from active components of analog front-end (AFE) circuit, which will be discussed in this paper, especially on the trans-impedance amplifier (TIA) domain. The noise characteristics of AFE circuit in VLC system has been analyzed using the variety of available commercial Op Amp and different types of the photodiode ( $\mathrm{Si}, \mathrm{Si}$-PIN, Si APD). The approach of this research is based on analytical calculus and simulation using MATLAB ${ }^{\circledR}$. The results of this research show that the main factor that affecting the noise is $e_{n}$, the feedback resistor $\left(\mathrm{R}_{\mathrm{f}}\right)$, and junction capacitor in the photodiode $\left(\mathrm{C}_{\mathrm{j}}\right)$. Besides that, the design concept of multi channel TIA (8 channel) using IC Op Amp, with consideration of pin number of each Op Amp, supply needs, the initial value of $\mathrm{R}_{\mathrm{f}}$, converter to 8-DIP and feedback capacitor $\left(\mathrm{C}_{\mathrm{f}}\right)$ channel, also discussed in this paper.
\end{abstract}

Copyright $\odot 2018$ Institute of Advanced Engineering and Science. All rights reserved.

\section{Corresponding Author:}

Syifaul Fuada,

Microelectronic Engineering option,

Departement of Electrical and Engineering,

School of Electrical Engineering and Informatic Engineering,

Institut Teknologi Bandung (ITB),

Gd. Achmad Bakrie LABTEK VIII third floor, Jln. Ganesha 10, Kampus ITB Ganesha, ZIP: 40116,

Bandung City, West Java, Indonesia.

Email: syifaulfuada@students.itb.ac.id

\section{NOMENCLATURE}

$\begin{array}{lll}\text { APD } & : & \text { Avalanche photodiode } \\ \text { GBW } & : & \text { Gain Bandwidth Product } \\ \mathrm{N}_{\text {voltage }} & : & \text { Voltage noise } \\ \mathrm{N}_{\text {current }} & : & \text { Current noise } \\ \mathrm{N}_{\mathrm{Rf}} & : & \text { Feedback Resistor noise } \\ \mathrm{N}_{\text {total }} & : & \text { Total noise in RMS } \\ \text { Op Amp } & : & \text { Operational amplifier } \\ \mathrm{PIN} & : & \text { Positive-Intrinsic-Negative } \\ \mathrm{Si} & : & \text { Silicon } \\ \mathrm{TIA} & : & \text { Trans-impedance amplifier } \\ \text { VLC } & : & \text { Visible Light Communications }\end{array}$




\section{INTRODUCTION}

Trans-impedance Amplifier (TIA) is one of the circuits which are widely used for optical wireless communication (OWC), e.g. Visible Light Communication (VLC). This device is often used as part of the analog front-end (AFE) circuit. Moreover, TIA also widely used for precision light measurement purpose. In the AFE circuit, TIA is the first block of the OWC receiver, which converts the electricity from current domain to voltage domain. This circuit is critical because its performances can determine the receiving side performances of VLC system. There are several parameters to design TIA, those are Bandwidth, Gain, Noise, and Sensitivity. On VLC application, TIA needs to have wide bandwidth and low noise characteristics. In some cases, high sensitivity characteristics also needed [1]. Therefore, there are many considerations to design the TIA circuit, either using discrete components or MOS layout.

Noise modeling and analysis is one of an important issue in VLC channels [2]. Noise is the most important parameters to determine signal to noise ratio (SNR) in the OWC network. Basically, there are two types of noise (i.e. external noise and internal noise). Internal noise is present in each component of the analog circuits of AFE of the VLC system which can affect and degrade the quality of signal and data. The active component, e.g. Op Amp has natural internal noise called $\mathrm{e}_{\mathrm{n}}, \mathrm{i}_{\mathrm{n}}$ and also intrinsic capacitance called $\mathrm{C}_{\mathrm{in}}$. Then, the photodiode as sensor device ideally has an intrinsic capacitance/ junction capacitor $\left(\mathrm{C}_{\mathrm{j}}\right)$ and intrinsic resistance/ shunt resistor $\left(\mathrm{R}_{\mathrm{sh}}\right)$. Those variables can be used as consideration for the component selection to design TIA circuit. The larger $\mathrm{e}_{\mathrm{n}}, \mathrm{i}_{\mathrm{n}}, \mathrm{C}_{\mathrm{in}}$ or $\mathrm{C}_{\mathrm{j}}$, the larger the noise on TIA.

Exploring noise behavior in TIA circuit should be investigated in VLC. This study is useful to predict the effects by using various parameters and characteristics, such as different Op Amp and also photodiode. It can be employed in VLC and trade-offs should be made between the complexity, performances, reliability, and cost. The contribution of this work is to study the effect of noise behavior at TIA by using a variety of commercial IC Op Amp and photodetector (silicon, Positive-Intrinsic-Negative, Avalanche). It can be used to accurately predict the performance when using different types of these two devices and can be used to design TIA with multichannel. Actually, we have studied about noise and bandwidth consideration of TIA in VLC system [3]. However, it is lack of discussion of the comparison of different varieties of the photodiode and Op Amp. Related noise analysis scheme is presented in [4] who modeled relative intensity noise (RIN) and thermal noise of the TIA on the optical coherent receiver. Then [5] analyze optical excess noise and thermal noise in two photodiodes (PIN and APD). This paper, focusing on the noise of TIA domain using Op Amp as a dependent variable and photodiode as independent variable to found characteristics such as $\mathrm{N}_{\text {voltage }}, \mathrm{N}_{\text {current }}, \mathrm{N}_{\mathrm{Rf}}$ and total noise $\left(\mathrm{N}_{\text {total }}\right)$.

Discussion on this paper is divided into 5 primary sections, first is the background which discusses the importances of noise behavior study of TIA in VLC system. The second part, explain research method and steps of the experiments. The second parts contain three sections, i.e. TIA description, the photodiode and Op Amp selection, and experimental procedure based on analytical calculus. The third part contains results and analysis of the experiments, those are a) Effect of changing the feedback resistor $\left(R_{f}\right)$ value on $\mathrm{N}_{\text {total }}$, b) Effect of the $\mathrm{C}_{\mathrm{j}}$ of the photodiode on the $\mathrm{N}_{\text {total }}$, and c) Effect of frequencies on the $\mathrm{N}_{\text {total }}$. Then, the fourth part contains the conclusion and the fifth part contains acknowledgment and references.

\section{METHODS}

The steps of this noise simulation experiments is shown in Figure 1, where there are 12 steps, starting from modelling of the overall VLC system, photodiode selection, considering amplifier IC types from several IC producers, selecting the Op Amps, mapping the Op Amps specification into the tables, calculate $\mathrm{R}_{\mathrm{f}}$, calculate $\mathrm{C}_{\mathrm{f}}$, calculate noise on TIA circuit, plotting the parameters, then buying and stocking the components, develop the DIP-8 IC converter and the last is developing the multichannel TIA kit. We use the eight Op Amps from the different manufacturer to observe the application potential of each IC with different characteristics.

In line with the experimental procedure that shown in Figure 1, the first step of this experiment will be explained in section 2.1., the second step will be explained in section 2.2., then the third, fourth and fifth step will be explained in section 2.3., The most important step of this experiment, the sixth, seventh and eighth steps, where the mathematical equation is done, will be explained in section 2.4., The results and analysis then will be explained in section 3 . 


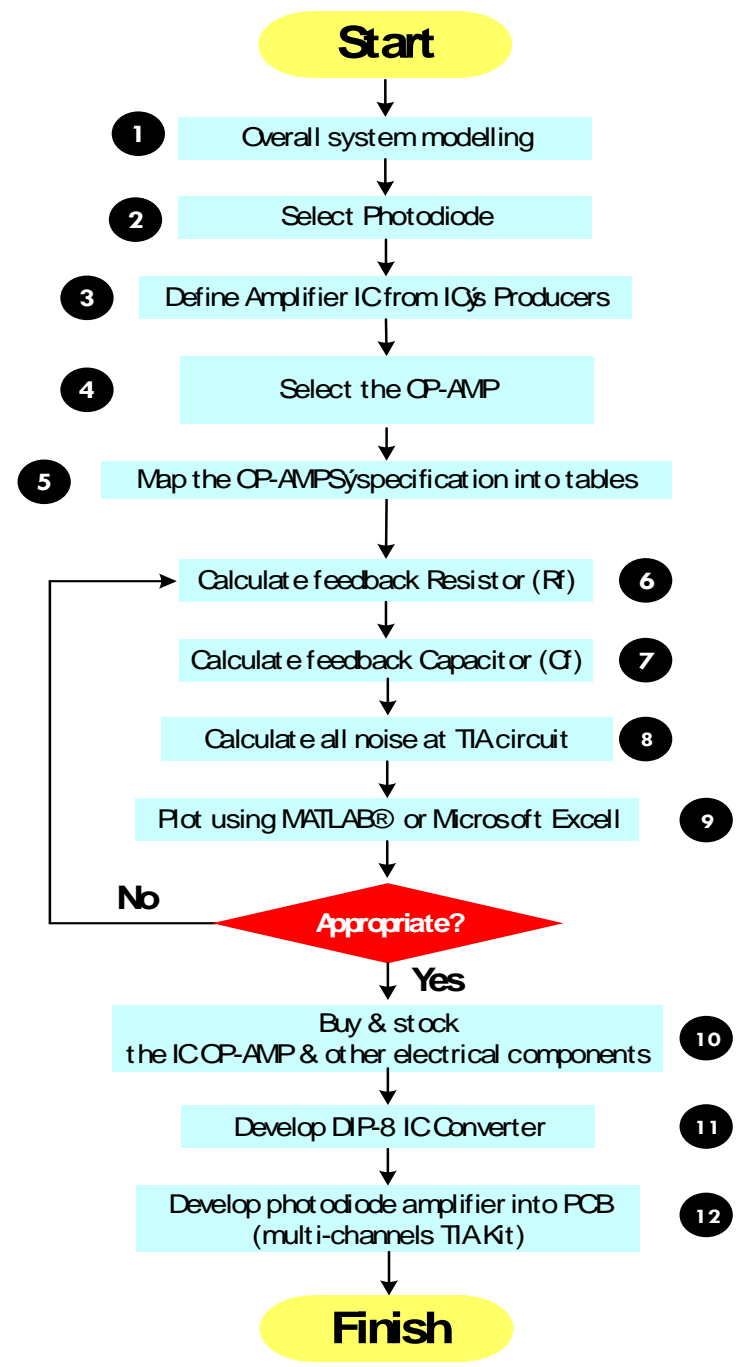

Figure 1. Experiment methodology

\subsection{Description of Multichannels TIA}

Figure 2 shows general OWC link for intensity modulation based VLC which cover system block, interferences signal \& external noises, internal noises and challenges in VLC system (e.g. Fading and shadowing). We adopted Figure 2 from Karunatilaka, et al [6] link structure and then mixed with noise models from K. Sindhubala, et al [7], major limitation model in VLC system from N. Noshad, et al [8] and noise models from Orozco [9]. On the channel parts, it is shown that as long as light propagating on the free space, the signal will be affected by interferences, such as from intercell-VLC interference [10], other noninformation light sources [11], shadowing effect caused by passive blocking object (e.g. indoor appliances or active blocking object), by people moving or human blocking [12], [13], and fading, which caused by uneven distribution of light and distance from the transmitter to receiver.

The detailed explanation of Figure 2 is not included in this paper. The focus of this paper is on AFE domain, especially the TIA domain. The photodetector receives information light from LED and generates $I_{r e c}$ current, which then converted into $V_{\text {rec }}$ voltage by the amplifier. The received signal on this photodiode contains noise, i.e. the external source noise from the environment or ambient light (sunlight, incandescent, fluorescent, flashlight and generic LED lamp). Then, on the AFE domain, noise is commonly seen in active component or amplifiers such as shot noise/Schottky, flicker noise (1/f), thermal noise/ Johnson-Nyquist noise (among other names) and nature quantizing fluctuation. Shot noise is generated by the statistical fluctuations of currents in the active components. Thermal noise is due to its equivalent resistance and capacitance. On the photodetector side, noise also generated (e.g. Dark current and optical excess noise) [7]. These parameters should be added to the calculation to find the ideal received signal $\left(\mathrm{V}_{\text {sig }}\right)$ which then would be processed on the demodulator (digital domain). 
Typically, noise consists of voltages and currents which flow in the active (e.g. Op Amp) and passive circuits (e.g. R, L, C) which can be expressed as noise density $\left(\mathrm{E}_{\mathrm{n}}\right.$ and $\left.\mathrm{I}_{\mathrm{n}}\right)$. On the TIA domain, based on [9], there are 3 noises i.e. $\mathrm{R}_{\mathrm{f}}$ noise $\left(\mathrm{N}_{\mathrm{Rf}}\right)$, current noise $\left(\mathrm{N}_{\text {current }}\right)$, and voltage noise $\left(\mathrm{N}_{\text {voltage }}\right)$. We must also include noise from the extra capacitance $\left(\mathrm{C}_{\mathrm{c}}\right)$ if the circuit is implemented on the project board or using selector switch and I/O terminal. Figure 3(a) adapted from [14] shows the TIA circuit with the photovoltaic topology which is used in this experiment. Figure $3(\mathrm{~b})$ is an equivalent model of TIA $\left(\mathrm{R}_{\mathrm{sh}}\right.$ on the photodiode is ignored). In this paper, the noise in TIA circuit based on the root mean square (RMS) of these three noises is analyzed.

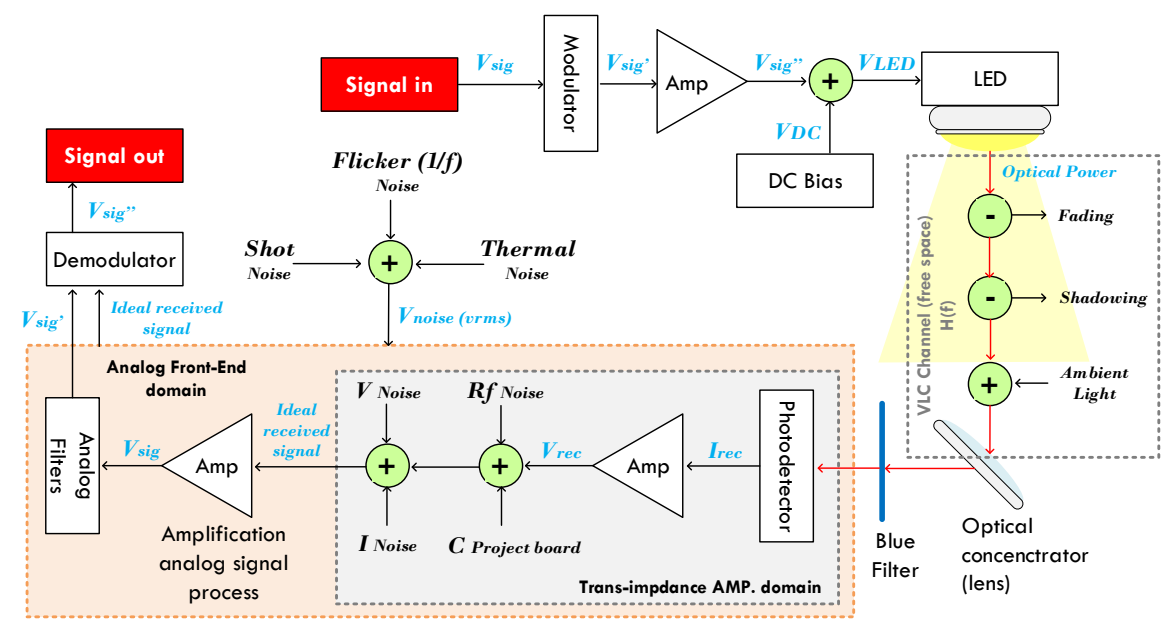

Figure 2. OWC link structure based VLC

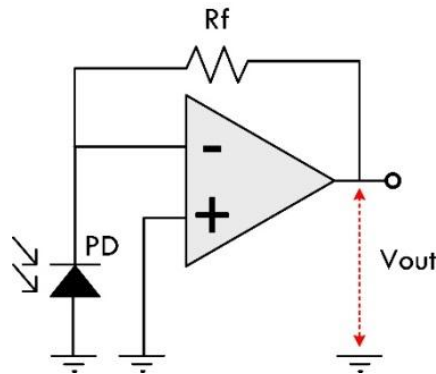

(a)

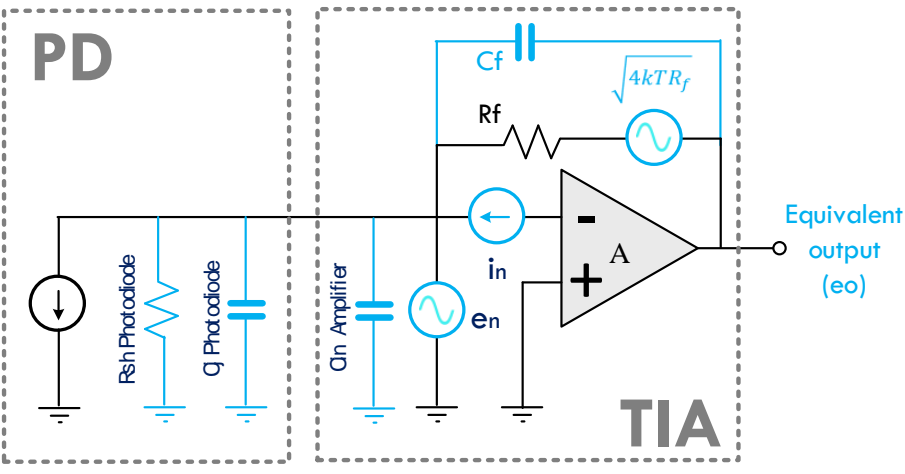

(b)

Figure 3. Generic TIA circuit based Op Amp: (a) photovoltaic mode; (b) Equvalent circuit

\subsection{Selected Photodiode}

VLC is one of the OWC which uses visible wavelength with the electromagnetic spectrum of $380 \mathrm{~nm}-780 \mathrm{~nm}$ [15-16]. To receive a signal from that spectrum, we need to use photodetectors, such as phototransistor or photodiode. The Photodiode is more recommended because it has better linearity, dynamic range, and stability. It also has a wide operation wavelength, $200 \mathrm{~nm}-2000 \mathrm{~nm}$ which also includes visible light wavelength. Although, the phototransistor has advantages on its low-cost price [17]. For experimental needs, we use three types of the photodiode. All of those are manufactured by HAMAMATSU, in which the types are Si PIN (320 nm - $1100 \mathrm{~nm})$, Si APD (200 nm to $1000 \mathrm{~nm})$ and Si (380 nm to $780 \mathrm{~nm})$.

Exploration of many photodiode types is also an open research topic in VLC [11], in which we also have already discussed this topic in another paper [18], [19]. But, we use photodiode only to find the intrinsic capacitance variable $\left(\mathrm{C}_{\mathrm{in}}\right)$ to analyze the noise characteristic on TIA domain. So several factors, such as area, 
rise time, cut-off frequency, dark current and short circuit current are not included as the main consideration, even though on the real implementation, those factors must be considered. The first step of this experiment is by choosing three different types of the photodiode, especially with significant differences on $\mathrm{pF}$ parameter, i.e. $3 \mathrm{pF}, 30 \mathrm{pF}$, and $150 \mathrm{pF}$. Detail of photodiode specification is listed in Table 1.

Table 1. Specification of Selected Photodiode

\begin{tabular}{|c|c|c|c|c|}
\hline No & Parameters & & Value & \\
\hline 1 & Series & S5821-3 & S9075 & S9219-01 \\
\hline 2 & Features & $\begin{array}{l}\text { High performance, high } \\
\text { reliability Si PIN } \\
\text { photodiodes }\end{array}$ & $\begin{array}{l}\text { Short wavelength } \\
\text { type APD, for } 600 \\
\text { nm band }\end{array}$ & $\begin{array}{l}\text { Spectral response like } \\
\text { human eye }\end{array}$ \\
\hline 4 & Producer & HAMAMATSU & HAMAMATSU & HAMAMATSU \\
\hline 5 & Type & Si PIN & Si APD & $\mathrm{Si}$ \\
\hline 6 & Package & TO-18 & TO-5 & TO-5 \\
\hline 7 & Spectral response range $\lambda$ & 320 to $1100 \mathrm{~nm}$ & 200 to $1000 \mathrm{~nm}$ & 380 to $780 \mathrm{~nm}$ \\
\hline 8 & Short circuit current (Isc) at 100 lux & $12 \mu \mathrm{A}$ & NA & $0.5 \mu \mathrm{A}$ \\
\hline 9 & Dark Current (Id) & $2 \mathrm{nA}$ & $15 \mathrm{nA}$ & $50 \mathrm{pA}$ \\
\hline 10 & Rise Time & NA & NA & $0.5 \mu \mathrm{s}$ \\
\hline 11 & Cut off frequency & $25 \mathrm{MHz}$ & $100 \mathrm{MHz}$ & NA \\
\hline 11 & Terminal Capacitance $(\mathrm{Ct})$ at $\mathrm{VR}=0 \mathrm{~V}$ & $3 \mathrm{pF}$ & $30 \mathrm{pF}$ & $150 \mathrm{pF}$ \\
\hline 12 & Photodiode Shunt Resistor (Rsh) & NA & $\mathrm{NA}$ & NA \\
\hline 13 & Noise Equivalent Power (NEP) & $6.7^{-15} \mathrm{~W} / \sqrt{ } \mathrm{Hz}$ & NA & NA \\
\hline 14 & Photosensitive area size & $\phi 1.2 \mathrm{~mm}$ & $\phi 1.5 \mathrm{~mm}$ & $3.6 \mathrm{~mm} \times 3.6 \mathrm{~mm}$ \\
\hline 15 & Reverse Voltage (VR) Max. & $20 \mathrm{~V}$ & NA & NA \\
\hline
\end{tabular}

\subsection{Selected Op Amp}

According to the introductory paragraph, there are several Op Amps criteria which need to be considered on TIA design, those are: a) High Bandwidth, b) Low Noise, c) Low power consumption, d) has good stability and sensitivity, e) large gain, then the last one is f) that components are commercially available in the markets.

To obtain those features, general Op Amp can't be included in Op Amp selection for TIA. Op Amp IC as the main variable is randomly chosen from several IC manufacturer which produce 'amplifier and

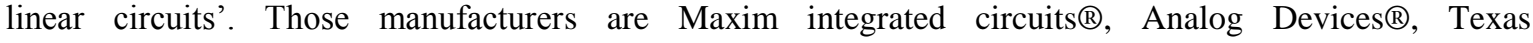
Instruments $\AA$, Linear Technologies $®$, Microchips $\AA, \quad$ ROHM $®$, Intersil®, and Fairchild or ON semiconductor ${ }^{\circledR}$ where each manufacturer produces Op Amp with suitable features to develop the TIA circuit. Specification detail of each manufacturer is shown in Table 1 which contains the specification of MAX9637, AD8014, OPA380, LTC6268C, MCP651, BA2107G, ISL55001 and FAN4852 from its datasheet.

There are 14 variables that needs to be considered, those are IC manufacturer, IC series, packaging type, quantity of Op Amp in one chip (channel), intrinsic capacitances of $\mathrm{IC}\left(\mathrm{C}_{\mathrm{in}}\right)$ in $\mathrm{pF}$, input current noise of IC $\left(\mathrm{E}_{\mathrm{n}}\right)$ in $\mathrm{nV} / \sqrt{\mathrm{Hz}}$, input $\mathrm{N}_{\text {voltage }}$ of IC $\left(\mathrm{I}_{\mathrm{n}}\right)$ in $\mathrm{fA} / \sqrt{\mathrm{Hz}}$ (pA units must be converted to Femto ampere for ISL55001 and AD8014), maximum positive supply voltage (V+) to minimum negative supply voltage (V-), output voltage swing capabilities $\left(\mathrm{V}_{\text {out }}\right)$, gain of $\mathrm{IC}\left(\mathrm{A}_{\mathrm{VOL}}\right)$ in $\mathrm{dB}$ unit or $\mathrm{V} / \mathrm{V}$, gain bandwidth product of IC $(\mathrm{GBW})$ in $\mathrm{MHZ}$, slewrate IC in $\mathrm{V} / \mu \mathrm{s}$ unit, power consumption in $m$ Watt and input bias current $\left(\mathrm{I}_{\mathrm{B}}\right)$. Cost factor $(\$)$ is not considered in this experiment.

From Table 1, it can be shown that not every parameter is available on the datasheet, e.g. BA2107G, in which $C_{i n}$ and $I_{n}$ is not available. So, for simulation needs, $C_{i n}$ is assumed to be $1 p F$, and $I_{n}$ is assumed to be $10 \mathrm{fA} / \sqrt{\mathrm{Hz}}$. The assumption is based on the comparison with OPA380. The approximation of $\mathrm{I}_{\mathrm{n}}$ and $\mathrm{C}_{\mathrm{in}}$ value can be done by comparing it with MCP651 specification with $\mathrm{e}_{\mathrm{n}}$ of around $7 \mathrm{nV} / \sqrt{\mathrm{Hz}}$. But, for heterogeneous of simulation data, we choose to approximate those values from the characteristic similarity with $\mathrm{C}_{\mathrm{in}}$ and $\mathrm{I}_{\mathrm{n}}$ from OPA380.

The most important variables for this noise characteristic simulation is $E_{n}, I_{n}$, and $C_{\text {in }}$ from each Op Amp IC. Bandwidth target of this OWC project is $\sim 1 \mathrm{MHz}$, therefore capabilities and range of operation of Op Amp has to be larger than the target bandwidth. In this case, MAX9637 with gain bandwidth product (GBW) of $1.5 \mathrm{MHz}$ is acceptable. According to [20], that besides $\mathrm{I}_{\mathrm{n}}, \mathrm{E}_{\mathrm{n}}$ and $\mathrm{C}_{\mathrm{in}}$ which is the input noise, there are other parameters that need to be considered in Op Amp selection, those are: a) large open loop gain, so that sensitivity of TIA is not affected by external capacitor that connected to Op Amp (minimal $>50 \mathrm{~dB}$ ), b) low input bias current, to minimize the dc output error and precise setting of $\mathrm{R}_{\mathrm{f}}$ (in pico-Ampere scale), c) bandwidth and slewrate, with large bandwidth amplifier stability can be maintained with ideal capabilities of Op Amp for high-rate OWC such as VLC is $>100 \mathrm{~V} / \mu \mathrm{s}$. Then, the limitation of Op Amp that is chosen for

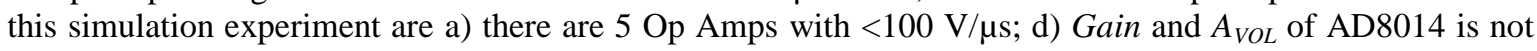

Noise Analysis of Trans-impedance Amplifier (TIA) in Variety Op Amp for use in .... (Syifaul Fuada) 
available on the datasheet and e) power consumption characteristic data is not available. Therefore, input noise is used as main parameters for the simulation and implementation. Table 2 shows the specification of Selected Op Amp

Table 2. Specification of Selected Op Amp

\begin{tabular}{|c|c|c|c|c|c|c|c|c|c|c|}
\hline No & Symbol & Parameter & & & & & & & & \\
\hline 1 & - & Producent & Maxim & $\begin{array}{c}\text { Analog } \\
\text { Devices }\end{array}$ & $\begin{array}{c}\text { Texas } \\
\text { Instruments }\end{array}$ & LT & Microchips & ROHM & Intersil & ON Semi \\
\hline 2 & - & Series & MAX9637 & $\begin{array}{c}\mathrm{AD} \\
8014\end{array}$ & OPA 380 & LTC6268C & MCP651 & BA2107G & ISL55001 & FAN4852 \\
\hline 3 & - & Package & $8 \mathrm{SC} 70$ & SOIC-8 & $\begin{array}{l}\text { MSOP-8, } \\
\text { SO-8 }\end{array}$ & $\begin{array}{l}8 \text { Lead } \\
\text { plastic SO }\end{array}$ & $\begin{array}{l}8 \text { Lead } \\
\text { SOIC }\end{array}$ & MSOP-8 & 8 LD SO & MSOP-8 \\
\hline 4 & - & channel & 2 & 1 & 1 & 1 & 1 & 2 & 1 & 2 \\
\hline 5 & $\left(\mathrm{C}_{\mathrm{in}}\right)$ & $\begin{array}{l}\text { Capacitor } \\
\text { input }(\mathrm{pF})\end{array}$ & 2 & 2.3 & 1.1 & 0.550 & 5 & NA & 1 & 17 \\
\hline 6 & $\left(E_{n}\right)$ & $\begin{array}{l}\text { Input noise } \\
\text { voltage } \\
\text { density } \\
(\mathrm{nV} / \sqrt{\mathrm{Hz}})\end{array}$ & 38 & 3.5 & 5.8 & 4.9 & 7.5 & 7 & 12 & 10 \\
\hline 7 & $\left(I_{n}\right)$ & $\begin{array}{l}\text { Input noise } \\
\text { current } \\
\text { density } \\
\text { (fA } \sqrt{\mathrm{Hz}} \text { ) }\end{array}$ & 0.9 & 5000 & 10 & 5.3 & 4 & NA & 1500 & 5 \\
\hline 8 & $\begin{array}{c}V+\& \\
V-\end{array}$ & $\begin{array}{l}\text { Supply } \\
\text { range (Volt) }\end{array}$ & +2.1 to +5 & $\begin{array}{l} \pm 2.25 \\
\text { to } \pm 6\end{array}$ & $\begin{array}{l} \pm 2.5 \text { to } \\
\pm 5.5\end{array}$ & $\begin{array}{l} \pm 3.1 \text { to } \\
\pm 5.5\end{array}$ & $\begin{array}{c} \pm 2.5 \text { to } \\
\pm 5.5\end{array}$ & \pm 1 to \pm 7 & $\begin{array}{l} \pm 2.25 \text { to } \\
\quad \pm 15\end{array}$ & $\begin{array}{c}+3.3 \text { to } \\
+5\end{array}$ \\
\hline 9 & $\left(\mathrm{~V}_{\text {out }}\right)$ & $\begin{array}{l}\text { Max. output } \\
\text { voltage } \\
\text { swing (Volt) }\end{array}$ & NA & $\begin{array}{c} \pm 3.6 \text { to } \\
\pm 4\end{array}$ & \pm 3.7 & \pm 5.25 & \pm 5 & +7 & \pm 11.5 & +4.5 \\
\hline 10 & $\left(\mathrm{~A}_{\mathrm{VOL}}\right)$ & $\begin{array}{l}\text { Large signal } \\
\text { voltage gain } \\
\text { Gain }\end{array}$ & $124 \mathrm{~dB}$ & NA & $120 \mathrm{~dB}$ & $250 \mathrm{~V} / \mathrm{mV}$ & $123 \mathrm{~dB}$ & $80 \mathrm{~dB}$ & $17 \mathrm{Kv} / \mathrm{V}$ & $120 \mathrm{~dB}$ \\
\hline 11 & $(\mathrm{GBW})$ & $\begin{array}{l}\text { Bandwidth } \\
\text { Product } \\
(\mathrm{MHz})\end{array}$ & 1.5 & 400 & 90 & 500 & 50 & 12 & 70 & 9 \\
\hline 12 & (SR) & $\begin{array}{l}\text { Slewrate } \\
(V / \mu \mathrm{s})\end{array}$ & 0.9 & 4000 & 80 & 400 & 30 & 4 & 280 & 6.2 \\
\hline 13 & $(\mathrm{~W})$ & $\begin{array}{l}\text { Power } \\
\text { consumption }\end{array}$ & $245 \mathrm{~mW}$ & $0.75 \mathrm{~W}$ & NA & NA & NA & $0.67 \mathrm{~W}$ & NA & NA \\
\hline 14 & $\mathrm{I}_{\mathrm{B}}$ & $\begin{array}{l}\text { Input } \\
\text { current bias }\end{array}$ & $\begin{array}{c}0.1-0.8 \\
\mathrm{pA}\end{array}$ & $\begin{array}{c}5-15 \\
\mu \mathrm{A}\end{array}$ & $3-50 \mathrm{pA}$ & $3-20 \mathrm{fA}$ & $6 \mathrm{pA}$ & $\begin{array}{c}150-400 \\
n A\end{array}$ & $\begin{array}{c}1.72-3.5 \\
\mu \mathrm{A}\end{array}$ & $\begin{array}{c}0.1-10 \\
\mathrm{pA}\end{array}$ \\
\hline
\end{tabular}

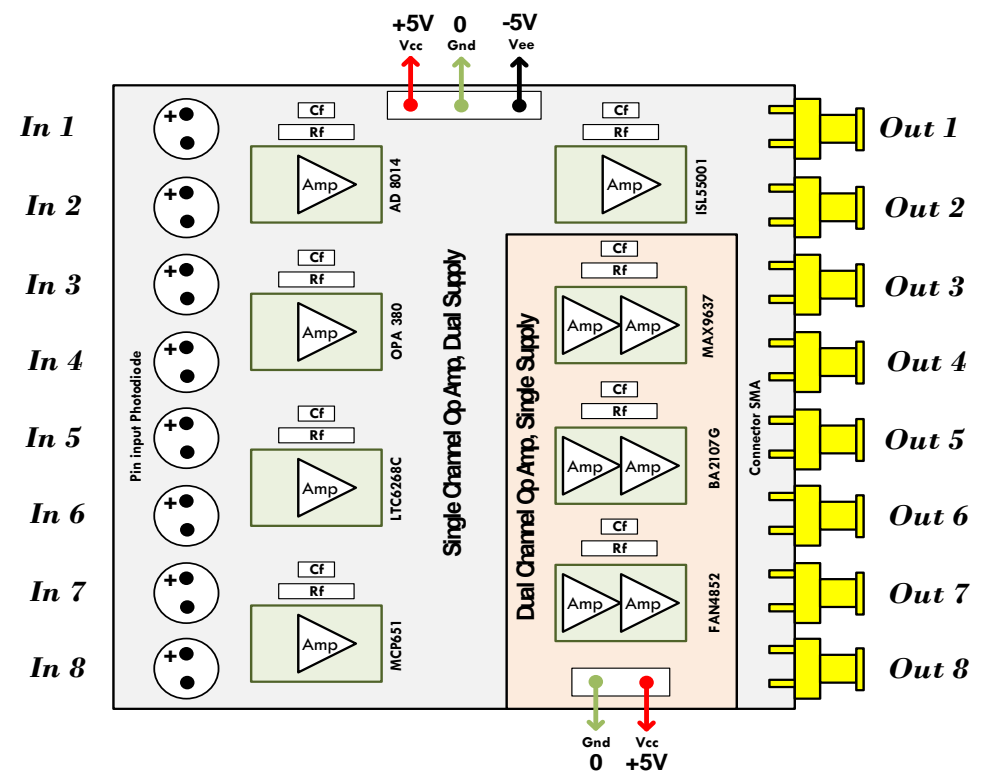

Figure 4. A printed circuit board concept of the 8 channels TIA. The multi-TIA board is connected to the detector and next stage amplifier 
From those eight chosen IC, there are three IC which has 2 channel, those are FAN4852, BA2107G, and MAX9637. The others of the IC only have 1 channel. So that the circuit can be implemented as a plug and play to the TIA board, we need IC pin converter to DIP-8, e.g. SOIC-8 to DIP-8, MSOP-8 to DIP-8, etc. Based on international reference guide, IC packaging of 8-pin Op Amp, the non-inverting pin is at number 2 and the inverting is at number 3. Whereas, the output is at number 6 for 1 channel Op Amp.

From the supply consideration, IC from Maxim and ON semiconductor only needs one input supply (single supply), those are MAX9637 ( $+2.1 \mathrm{~V}_{\mathrm{DC}}$ to $\left.+5 \mathrm{~V}_{\mathrm{DC}}\right)$ and FAN4852 (+3.3 $\mathrm{V}_{\mathrm{DC}}$ to $\left.+5 \mathrm{~V}_{\mathrm{DC}}\right)$. The others of the IC can be used for double supply. The planning of TIA board based on the specification of the above 8 chosen IC, needs the single/double power supply and the number of the channel on Op Amp IC. The board or kit that wants to be developed is "8-channels input TIA", which concept is shown in Figure 4. We use a variable resistor with value of $100 \mathrm{k} \Omega$ so that the output voltage can be tuned as desired.

\subsection{Experiment Procedure}

TIA or photodiode amplifier consists of single/array photodiode, IC Op Amp, $\mathrm{R}_{\mathrm{f}}$, and $\mathrm{C}_{\mathrm{f}}$. The key elements of this design are the photodiode \& Op Amp selection and then $\mathrm{R}_{\mathrm{f}} \& \mathrm{C}_{\mathrm{f}}$ calculation. The working principles of TIA is converting the light signal received by photodiode into current, then that weak current is flowing through the resistor, converted into voltage and amplified by the Op Amp. The general equation of TIA is $V_{\text {out }}=I_{p d} * R_{f}$. The resistor serves as a gain of the amplifier because $I_{p d}$ is constant and limitation of the photodiode to generates current, depended on the intensity of the light. The value of the resistor can be determined corresponding to the maximum current of photodiode and desired $\mathrm{V}_{\text {out }}$ (Equation (1)). The larger the value of the resistor, the larger the value of $\mathrm{V}_{\text {out }}$ [21], but gain determination has to be done carefully on TIA design for the OWC. Because it can affect the bandwidth to be narrow and the signals can be clipped. The detailed description of bandwidth is beyond the scope of this paper.

$$
\mathrm{R}_{\mathrm{f}}=\frac{\text { Vout }_{\text {max. }}-\text { Vout }_{\text {min. }}}{\text { i photodiode }_{(\max .)}}
$$

The capacitors also have important role in reducing the noise, optimizing the TIA response, determines the stability of TIA circuit, and also in reducing the overshoot. The larger the $\mathrm{C}_{\mathrm{f}}$, the slower the response of the TIA and the smaller the $\mathrm{C}_{\mathrm{f}}$, so that the amplifier is oscillating, even though it increases the bandwidth. The value of $\mathrm{C}_{\mathrm{f}}$ forms a pole in the frequency response with $45^{\circ}$ of phase margin, is given by Equation (2), where $C_{j}$ is photodiode's shunt capacitances in Farad and $C_{i n}$ is Op Amp input capacitances in Farad. Therefore the maximum value of $\mathrm{C}_{\mathrm{f}}$ can be determined from the desired bandwidth (in this case we use $1 \mathrm{MHz}$ frequency as gain bandwidth product (GBW).

$$
\mathrm{C}_{\mathrm{f}}=\sqrt{\frac{\mathrm{C}_{\mathrm{J}}+\mathrm{C}_{\mathrm{in}}}{2 \pi * \mathrm{R}_{\mathrm{f}} * \mathrm{fGBW}}}
$$

Then the peak noise can be determined based on Equation (3). With assumptions in which the first zero and pole of the noise density output less a decade lower than the second pole and which the output noise is equal to the plateau noise $\left(\mathrm{N}_{2}=\right.$ plateau noise), where $\mathrm{e}_{\mathrm{n}}$ is the voltage noise density obtained from the datasheet.

$$
\mathrm{N}_{2}=\mathrm{e}_{\mathrm{n}}\left(\frac{\mathrm{C}_{\mathrm{in}}+\mathrm{C}_{\mathrm{j}}+\mathrm{C}_{\mathrm{f}}}{\mathrm{C}_{\mathrm{f}}}\right)
$$

The calculation of $\mathrm{N}_{\text {voltage }}$ is based on Equation (4), where $\mathrm{N}_{2}$ is obtained from Equation (3) and $\mathrm{f}_{\mathrm{p} 2}$ are obtained from Equation (5). Then the $\mathrm{N}_{\text {voltage }}$ can be rewritten as Equation (6), The total sum of $\mathrm{C}_{\mathrm{j}}, \mathrm{C}_{\mathrm{in}}$, and $\mathrm{C}_{\mathrm{f}}$ is $\mathrm{C}_{\mathrm{tot}}$ or $\mathrm{C}_{\mathrm{t}}$ in Farad.

$$
\mathrm{N}_{\text {Voltage }}=\mathrm{N}_{2} \sqrt{\frac{\pi}{2} * \mathrm{f}_{\mathrm{p} 2}}
$$




$$
\begin{aligned}
& \mathrm{f}_{\mathrm{p} 2}=\mathrm{f}_{\mathrm{GBW}}\left(\frac{\mathrm{C}_{\mathrm{f}}}{\mathrm{C}_{\mathrm{in}}+\mathrm{C}_{\mathrm{j}}+\mathrm{C}_{\mathrm{f}}}\right) \\
& \mathrm{N}_{\text {Voltage }}=\mathrm{e}_{\mathrm{n}}\left(\frac{\mathrm{C}_{\mathrm{in}}+\mathrm{C}_{\mathrm{j}}+\mathrm{C}_{\mathrm{f}}}{\mathrm{C}_{\mathrm{f}}}\right) * \sqrt{\frac{\pi}{2} *\left(\frac{\mathrm{C}_{\mathrm{f}}}{\mathrm{C}_{\text {in }}+\mathrm{C}_{\mathrm{j}}+\mathrm{C}_{\mathrm{f}}}\right) * \mathrm{f}_{\mathrm{GBW}}}
\end{aligned}
$$

The Op Amp's current noise will appear on the output after going through the $\mathrm{R}_{\mathrm{f}}$, given by Equation (7), where $I_{n}$ is noise input density obtained from each Op Amp datasheet. ENBW, which is equivalent of noise bandwidth can be obtained using Equation (8). The calculation of TIA's cut-off frequency ( $\mathrm{f}_{-3 \mathrm{db}}$ ) is based on Equation (9).

$$
\begin{aligned}
& \mathrm{N}_{\text {current }}=\mathrm{I}_{\mathrm{n}} * \mathrm{R}_{\mathrm{f}} * \sqrt{\mathrm{ENBW}} \\
& \mathrm{ENBW}=\mathrm{f}_{-3 \mathrm{db}} * \frac{\pi}{2} \\
& \mathrm{f}_{-3 \mathrm{~dB}}=\sqrt{\frac{\mathrm{f}_{\mathrm{GBP}}}{2 \pi * \mathrm{R}_{\mathrm{f}} *\left(\mathrm{C}_{\mathrm{in}}+\mathrm{C}_{\mathrm{j}}\right)}}
\end{aligned}
$$

The noise in $\mathrm{R}_{\mathrm{f}}$ of TIA is given by Equation (10). Where $k$ is the Boltzmann $\left(1.38 \times 10^{-23}\right)$ constant and $T$ is the temperature in Kelvin $(283 \mathrm{~K})$.

$$
\mathrm{N}_{\text {Resistor-feedback }}=\sqrt{4 \mathrm{kT} * \mathrm{ENBW} * \mathrm{Rf}}
$$

The three noise sources in the mathematically calculation are independent. Gaussian means that the $\mathrm{N}_{\text {total }}$ is the root-sum-square (RSS), which given by Equation (11). The specific circuit of Low Pass Filter (LPF) on the TIA output can greatly reduce the $\mathrm{N}_{\text {total }}$ if $\mathrm{f}_{p}$ is much higher than the signal bandwidth by adding singlepole RC filters.

$$
\mathrm{N}_{\text {Total }}=\sqrt{\mathrm{N}_{\text {Resistor-feedback }}^{2}+\mathrm{N}_{\text {current }}^{2}+\mathrm{N}_{\text {voltage }}^{2}}
$$

\section{RESULTS AND ANALYSIS}

\subsection{Impact of the Higher $R_{f}$ Selection}

In this experiment, we use one type of photodiode as the parameters, that is silicon ( $\mathrm{Si}$ ) S9219-01 with characteristics $\mathrm{Cj}=150 \mathrm{pF}$ and one type of Op Amp IC, that is OPA380 "Precision, High-Speed Transimpedance Amplifier" with characteristics: $\mathrm{C}_{\mathrm{in}}=1.1 \mathrm{pF}, \mathrm{E}_{\mathrm{n}}=5.8 \mathrm{nV} / \sqrt{\mathrm{Hz}}$ and $\mathrm{I}_{\mathrm{n}}=10 \mathrm{fA} / \sqrt{\mathrm{Hz}}$. Because of the limitation of the space for the figure of the results, we use only four resistors with different values, those are $0.5 \mathrm{k} \Omega, 1 \mathrm{k} \Omega, 1.5 \mathrm{k} \Omega$ and $2 \mathrm{k} \Omega$. This simulation is using the calculation based on Equations (6), (7), (10) and (11). According to Figure 5, it can be shown that the value of $R_{f}$ is linear against the noise. The larger the value of $\mathrm{Rf}$, the larger the value of $\mathrm{N}_{\text {voltage }}, \mathrm{N}_{\text {current }}, \mathrm{N}_{\mathrm{Rf}}$ which affects the $\mathrm{N}_{\text {total }}$. This is consistent with the experimental results of [22] which prove the relation between gain and RMS noise. From this experiment, it can be concluded that $\mathrm{R}_{\mathrm{f}}$ is one of the main contributors to output noise. 


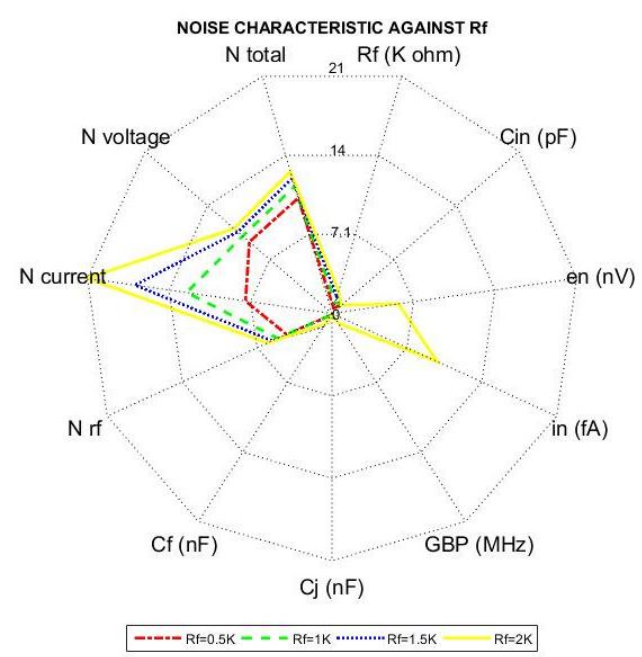

Figure 5. Relationship between noise (voltage, current, $\left.\mathrm{R}_{\mathrm{f}}\right)$ and noise total at different $\mathrm{R}_{\mathrm{f}}(0.5 \mathrm{k} \Omega, 1 \mathrm{k} \Omega, 1.5$ $\mathrm{k} \Omega$ and $2 \mathrm{k} \Omega$ ) when using OPA380

\subsection{Impact of the Difference Photodiodes}

Figure 6, Figure 7 and Figure 8 shows the characteristics of the eight investigated Op Amp. The Y-axis is scaled from -5 to 75 , because of the limitation of the space and it has a very wide gap (extremely low and extremely high) where the detail value can be shown in the table below the figure. The $\mathrm{X}$-axis shows the observed variables and the corresponding units. Variables $e_{n}, i_{n}$ and $C_{i n}$ are obtained from the datasheet of each Op Amp as fixed variable, whereas $\mathrm{C}_{\mathrm{f}}, \mathrm{N}_{\mathrm{Rf}}, \mathrm{N}_{\text {current }}, \mathrm{N}_{\text {voltage }}$, and $\mathrm{N}_{\text {total }}$ is based on the calculation of the section 2 point $\mathrm{D}$. The $\mathrm{R}_{\mathrm{f}}$ and GBW are independent variables.

Because on section 3 point $A$ the simulation has been done for $R_{f}=2 \mathrm{k} \Omega$ so that the simulation results are not repeated (heterogoneous of data), in this pont we use $R_{f}=2.2 \mathrm{k} \Omega$. The GBW is configured the same, $1 \mathrm{MHz}$. All of the noise is on micro $(\mu)$ units, except for $\mathrm{N}_{\text {current }}$ which is in nano (n) unit due to very low, and it is hard to see the gap of the low noise scale. For example, the differences between $\mathrm{N}_{\text {current }}$ which are insignificant using the micro scale, i.e. $\mathrm{LTC} 6268 \mathrm{C}=0.031$ with BA2107G $=0.05685$ with the maximum scale of 75. This will be easier to be shown if using nano scale, i.e. 31 and 56.

By using three types of the photodiode with the variated gap of $C_{j}$, we obtained interesting results. From the three figures, can be concluded that: a) the larger the $\mathrm{e}_{\mathrm{n}}$, the larger the $\mathrm{N}_{\text {voltage }}$ and the $\mathrm{N}_{\text {total }}$. It can be shown on MAX9637, even though it is really low. b) The smaller the $i_{n}$ the $N_{\text {current }}$ tends to be low, it can be shown from the significant differences between MAX9637 with OPA8014 and ISL55001. c) The value of $C_{j}$ affecting the $\mathrm{C}_{\mathrm{f}}$ significantly, that is the larger the $\mathrm{C}_{\mathrm{j}}$, the larger the $\mathrm{C}_{\mathrm{f}}$, and so does the opposite.

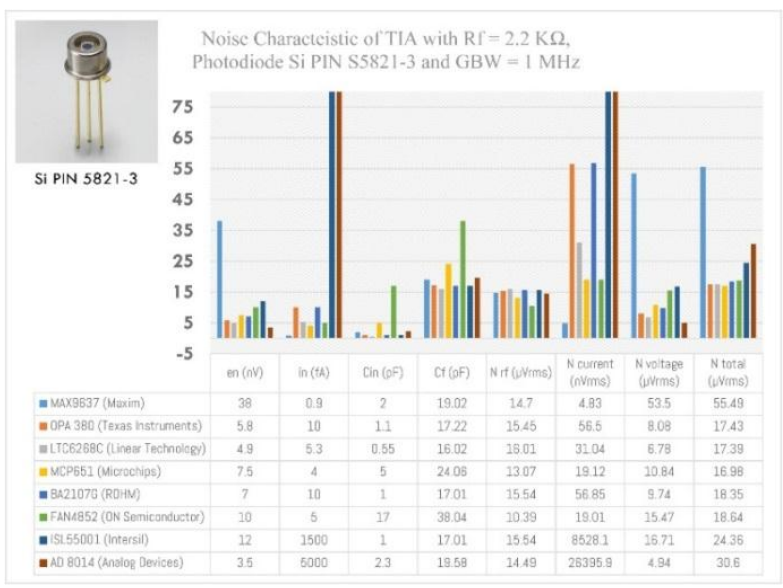

Figure 6. Noise characteristics in TIA circuit with $\mathrm{GBW}=1 \mathrm{MHz}$ and $\mathrm{R}_{\mathrm{f}}=2.2 \mathrm{k} \Omega$ when using Silicon PIN S5821-3 with $\mathrm{C}_{\mathrm{j}}=3 \mathrm{pF}$

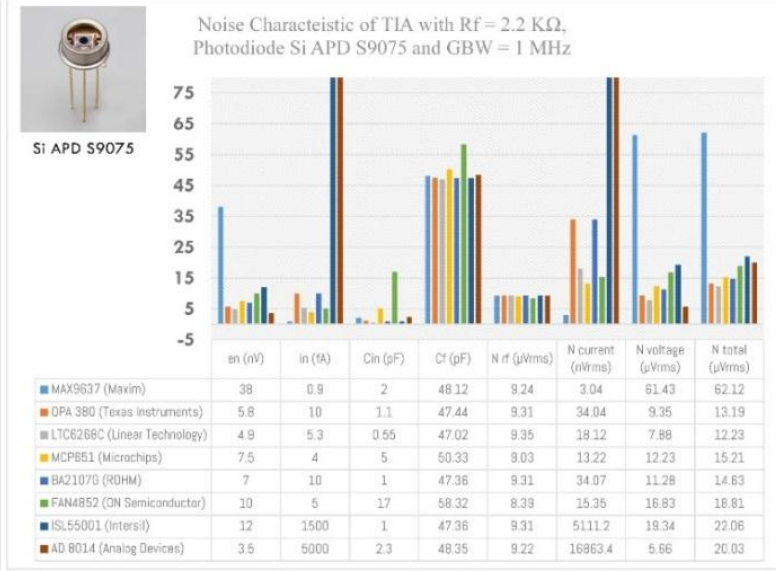

Figure 7. Noise characteristics in TIA circuit with $\mathrm{GBW}=1 \mathrm{MHz}$ and $\mathrm{R}_{\mathrm{f}}=2.2 \mathrm{k} \Omega$ when using Silicon APD S9075 with $\mathrm{C}_{\mathrm{j}}=30 \mathrm{pF}$ 


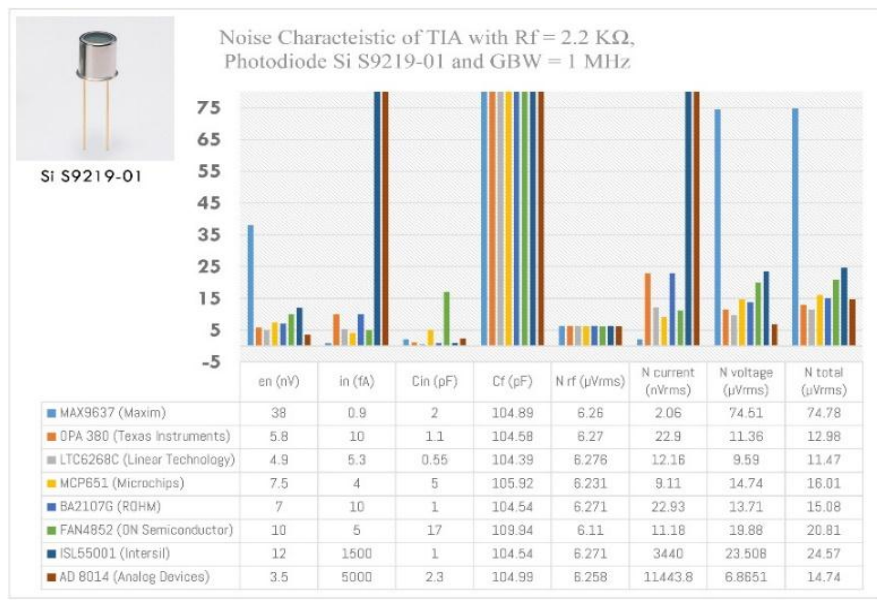

Figure 8. Noise characteristics in TIA circuit with $\mathrm{GBW}=1 \mathrm{MHz}$ and $\mathrm{R}_{\mathrm{f}}=2.2 \mathrm{k} \Omega$ when using Silicon S9219-01 with $\mathrm{C}_{\mathrm{j}}=150 \mathrm{pF}$

\subsection{Frequency and $\mathrm{Cj}$ as a Function of Total Noise $\left(\mathrm{N}_{\text {total }}\right)$}

Figure 9, Figure 10 and Figure 11 show the graphics of $\mathrm{N}_{\text {total }}$ in $\mu$ VRMS against frequency. The purpose of this experiment is to find the $\mathrm{N}_{\text {total }}$ behavior by variating the frequency, from $1 \mathrm{MHz}$ (the minimal bandwidth target) to $10 \mathrm{MHz}$, with interval of $2 \mathrm{MHz}$ and the value of $\mathrm{R}_{\mathrm{f}}$ is constant $1 \mathrm{k} \Omega$. Because of the space limitation for the figure of experiment results, in this point we only show the $\mathrm{N}_{\text {total }}$, so $\mathrm{N}_{\text {voltage }}, \mathrm{N}_{\text {current }}$, and $\mathrm{N}_{\mathrm{Rf}}$ are not simulated. From Figure 9, Figure 10 and Figure 11, it can be observed the $\mathrm{N}_{\text {total }}$ of each IC Op Amp is linear against the frequency range. The higher the frequency, the larger the $\mathrm{N}_{\text {total }}$. The difference in the value of $\mathrm{C}_{\mathrm{j}}$ of photodiode also affecting the noise, the larger the $\mathrm{C}_{\mathrm{j}}$, the larger the noise.

The graph shown the extreme noise and the stable noise. MAX9637 has the larger noise deviation and steep curve, it is because of its $\mathrm{e}_{\mathrm{n}}$ factor, which is larger than the other Op Amps, around $38 \mathrm{nV} / \sqrt{\mathrm{Hz}}$. So it affecting in the large $\mathrm{N}_{\text {total }}$, even though it has the lowest $i_{n}$, around $0.9 \mathrm{fA} / \sqrt{\mathrm{Hz}}$. Then, AD8014 has the largest $i_{n}$, around $5000 \mathrm{fA} / \sqrt{H z}$, so it has large noise even though the curve is slope, different with MAX9637. After that ISL5501 has an extreme characteristic with significant differences in the $i_{n}(1500$ $\mathrm{fA} / \sqrt{\mathrm{Hz}})$ with $\mathrm{C}_{\mathrm{in}}(1 \mathrm{pF})$ and $\mathrm{e}_{\mathrm{n}}(12 \mathrm{nV} / \sqrt{\mathrm{Hz}})$. So, the $\mathrm{N}_{\text {total }}$ is tends to be large, but with different graph form with AD8014 which has the combination of low $\mathrm{C}_{\text {in }}$ for large noise. LTC6268C has low $\mathrm{N}_{\text {total }}$, it is because it has lower $e_{n}, i_{n}$ and $C_{i n}$ than the others Op Amp. This experiment is only to shows the effect of noise, not for comparing performances of each product of IC manufacturer.

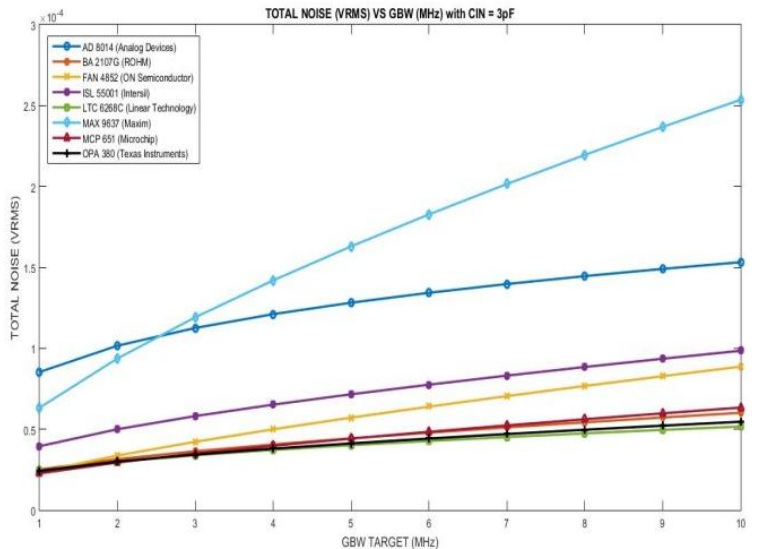

Figure 9. $\mathrm{N}_{\text {total }}$ in VRMS scale vs gain bandwidth product in frequency from $1 \mathrm{MHz}$ to $10 \mathrm{MHz}$ when using Silicon PIN S5821-3 with $\mathrm{C}_{\mathrm{j}}=3 \mathrm{pF}$

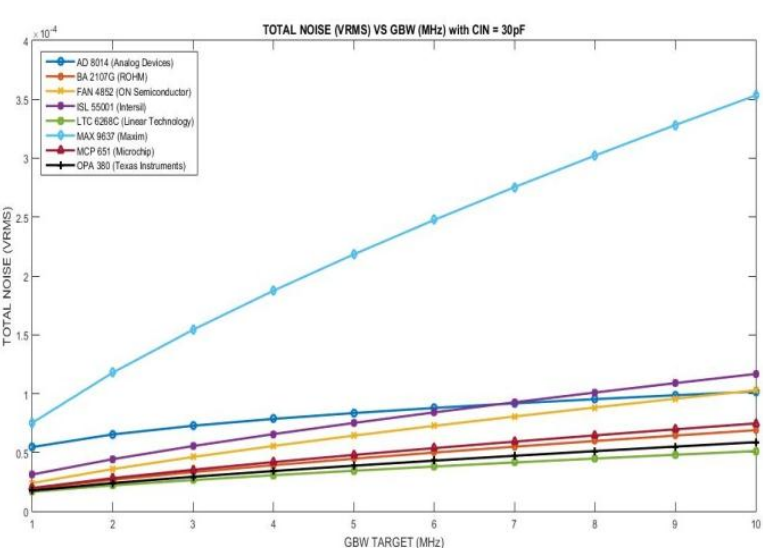

Figure 10. $\mathrm{N}_{\text {total }}$ in VRMS scale vs gain bandwidth product in frequency from $1 \mathrm{MHz}$ to $10 \mathrm{MHz}$ when using Silicon APD S9075 with $\mathrm{C}_{\mathrm{j}}=30 \mathrm{pF}$ 


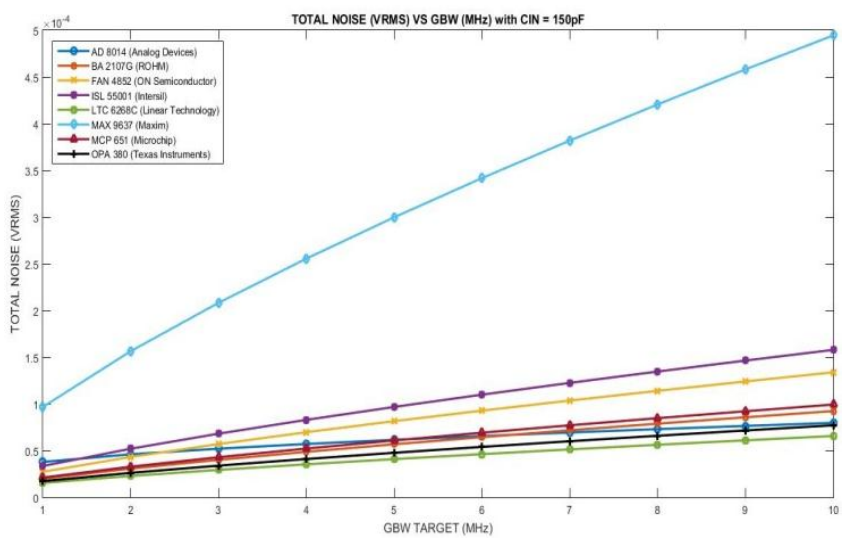

Figure 11. $\mathrm{N}_{\text {total }}$ in VRMS scale vs gain bandwidth product in frequency from $1 \mathrm{MHz}$ to $10 \mathrm{MHz}$ when using Silicon S9219-01 with $\mathrm{C}_{\mathrm{j}}=150 \mathrm{pF}$

\section{CONCLUSION}

In the last of several decades, the wireless communication has been adopted in many application [23-26]. VLC is one of the wireless communication optics-based that also popular to be implemented in our life, such as for indoor positioning system [27], audio transmission system [28] and etc. This technology can cover RF communication that can't exist in the closed area. In this paper, we focus on noise analysis in VLC system.

The noise characteristics of Op Amp for VLC applications based on analytical calculus has been described. According to the experiments, it can be shown that the main contributor to the output noise is the "voltage noise density" $\left(\mathrm{e}_{\mathrm{n}}\right)$ which comes from the Op Amp itself and from the external components, i.e. $\mathrm{R}_{\mathrm{f}}$. This experiment's results are consistents with results of [29], [30]. Besides that, the Cj, which is an internal characteristic of the commercial photodiode, also affecting the noise. The larger the $\mathrm{Cj}, \mathrm{e}_{\mathrm{n}}$, and Rf, the larger the $\mathrm{N}_{\text {total }}$ is. The concept of the fabrication method of multi-TIA with total Op Amp of 8 also has been explained, with consideration in the total amount of pin IC, amount of Op Amp in one IC, packaging type of IC and the amount of power supply. After this, we will assemble the real system based on discrete components, so we will be able to provide comparisons of the real implementation with the simulation results, which also be interesting as the topic of the next publication.

\section{REFERENCES}

[1] B. Fahs, A. Chowdhury, and M.M. Hella, “A Digitally Tunable Stabilization Technique for Transimpedance Amplifiers in Optical Wireless and Visible Light Communication Links, ” Proc. of the $14^{\text {th }}$ IEEE Int. New Circuits and Systems Conf. (NEWCAS), October 2016.

[2] O. Ergul, E. Dinc, and O.B. Akan, "Communicate to illuminate: State-of-the-art and research challenges for visible light communications," Physical Communication, Vol. 17, pp. 72 - 85, 2015.

[3] T. Adiono, R.V.W. Putra, and S. Fuada, "Noise and Bandwidth Considerations in Designing Op-Amp Based Transimpedance Amplifier for VLC," Unpublished.

[4] B. Zhang, C. Malouin, and T.J. Schmidt, "Design of coherent receiver optical front end for unamplified applications," Optics Express, Vol. 20(3), pp. 3225-3234, 2012.

[5] O. Kharraz and D. Forsyth, "Performance comparisons between PIN and APD photodetectors for use in optical communication systems," Optik Elsevier, Vol. 124, pp. 1493 - 1498, 2013.

[6] D. Karunatilaka, F. Zafar, V. Kalavally, and R. Parthiban, "LED Based Indoor Visible Light Communications: State of the Art," IEEE Communication Surveys \& Tutorials, Vol. 17(3), $3^{\text {rd }}$ Quarter, pp. 1649 - 1678, 2015.

[7] K. Sindhubala and B. Vijayalakshmi, "Review On Impact Of Ambient Light Noise Sources and Applications In Optical Wireless Communication Using LED," Int. J. of Applied Engineering Research, Vol. 10(12), pp. 31115 31130, 2015.

[8] M. Noshad and M. Brandt-Pearce, “Can visible light communications provide Gb/s service?” Aug. 2013, arXiv: 1308.3217

[9] L. Orozco, "Programmable-Gain Transimpedance Amplifiers Maximize Dynamic Range in Spectroscopy Systems, Analog Dialoue,” Vol. 47, May 2013. [Online] Available in http://www.analog.com/media/en/analogdialogue/volume-47/number-2/articles/programmable-gain-transimpedance-amplifiers.pdf.

[10] P.H. Pathak, et al, "Visible Light Communication, Networking, and Sensing: A Survey, Potential and Challenges," IEEE Communications Surveys \& Tutorials, Vol. 17(4), $4{ }^{\text {th }}$ Quarter, pp. 2047 - 2077, 2015. 
[11] L.U. Khan, "Visible light communication: Applications, architecture, standardization and research challenges," Digital Communications and Networks, 2016.

[12] T. Komine, S. Haruyama and M. Nakagawa, "A Study of Shadowing on Indoor Visible-Light Wireless Communication Utilizing Plural White LED Lightings," Wireless Personal Communications 34, pp. 211-225, 2005.

[13] H. Farahneh, et al, "Shadowing Effects on Visible Light Communication Channels," Canadian Conf. on Electrical and Computer Engineering (CCECE), 2016.

[14] B. Hussain, et al, "Visible Light Communication System Design and Link Budget Analysis," pp. 5201-5209, J. of Lightwave Technology, Vol. 33(24), December 2015.

[15] L. Feng, et al, "Applying VLC in 5G Networks: Architectures and Key Technologies," IEEE Network, pp. 12-18, 2016.

[16] C-W. Chow and C-H. Yeh, "Visible Light Communication," The Current Trends of Optics and Photonics, Chapter 4, topics in Applied Physics 129, pp. 107-127, 2015.

[17] L. Goodfrey, "Choosing the Detector for your Unique Light Sensing Application," [Online] Available at http://www.johnloomis.org/ece445/topics/egginc/tp4.html.

[18] S. Fuada and T. Adiono, "Pengaruh Junction Capacitor $\left(\mathrm{C}_{\mathrm{j}}\right)$ Photodiode terhadap Noise pada TIA untuk Aplikasi Visible Light Communications (VLC)," Unpublished.

[19] S. Fuada, A.P. Putra, and T. Adiono, "Analysis of Received Power Characteristics of Commercial Photodiodes in Indoor LoS Channel Visible Light Communication," Int. J. of Advanced Computer Science and Applications (IJACSA), Vol. 8(7), July 2017.

[20] M. Nakhostin, et al, "Use of commercial operational amplifiers in a low cost multi-channel preamplifier system," Radiation Physics and Chemistry, Vol. 85, pp. 18-22, 2013.

[21] S. Fuada, A.P. Putra, Y. Aska, and T. Adiono, "Trans-impedance Amplifier (TIA) Design for Visible Light Communication (VLC) using Commercially Available OP-AMP," Proc. of the $3^{\text {rd }}$ Int. Conf. on Information Tech. Computer, and Electrical Engineering (ICITACEE), pp. 31-35, October 2016.

[22] J. Wareberg, D. Kennedy, and S. Schmidt, "Design and Prototyping of a Transimpedance Front-end Amplifier for Dense Wavelength Division Multiplexing Circuits," [Online] available at http://www.microwavejournal.com/articles/3296-design-and-prototyping-of-a-transimpedance-front-endamplifier-for-dense-wavelength-division-multiplexing-circuits, September 2001.

[23] M. Chang and Q Wang, "Application of Wireless Sensor Network and GPRS Technology in development of Remote Monitoring System,” Int. J. of Electrical and Computer Engineering (IJECE), Vol. 13(1), pp. 151-158, January 2015.

[24] H. Ding, "Application of Wireless Sensor Network in Target Detection and Localization," Int. J. of Electrical Engineering and Computer Science (IJEECS), Vol. 11(10), pp. 5734-5740, October 2013.

[25] K.N. Qureshi, A.H. Abdullah, and R.W. Anwar, "Wireless Sensor Based Hybrid Architecture for Vehicular Ad hoc Networks," TELKOMNIKA (Telecommunication Computing Electronics and Control), Vol. 12(4), pp. 942949, December 2014.

[26] T. Adiono, R.V.W. Putra, M.Y. Fathany, B.L. Lawu, K. Afifah, M.H. Santriaji, S. Fuada, "Rapid prototyping methodology of lightweight electronic drivers for smart home appliances," Int. J. of Electrical and Computer Engineering (IJECE), Vol. 6(5), October 2016.

[27] M. Rahman, et al, "Indoor Positioning by LED Visible Light Communication and Image Sensors," Int. J. of Electrical and Computer Engineering (IJECE), Vol. 1(2), pp. 161-170, December 2011.

[28] S. Fuada, and T. Adiono, "Rancang Bangun Layer Fisik Visible Light Communication Pada Sistem Transmisi Audio," J. INFOTEL, Vol. 9(3), August 2017.

[29] S. Fuada, T. Adiono, A.P. Putra, and Y. Aska, "Noise Analysis in VLC Optical Link based Discrette OP-AMP Trans-Impedance Amplifier (TIA)," TELKOMNIKA (Telecommunication Computing Electronics and Control), Vol. 15(3), September 2017.

[30] L. Orozco, "Optimizing Precision Photodiode Sensor Circuit Design," Application note MS-2624, pp. 1-5, 2014. [Online] Available in http://www.analog.com/media/en/technical-documentation/technical-articles/OptimizingPrecision-Photodiode-Sensor-Circuit-Design-MS-2624.pdf.

\section{BIOGRAPHIES OF AUTHORS}

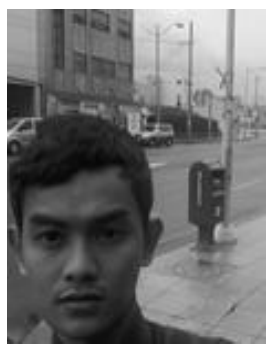

Syifaul Fuada received B.Ed degree on Electrical Engineering Education major from Universitas Negeri Malang (UM), Indonesia in 2014/2015 and Received M.Sc degree on Microelectronics Engineering major from Electrical Engineering Department, School of Eletrical Engineering and Informatics Institut Teknologi Bandung in 2016/2017. He holds two pending patents (helmet charger based solar energy and out-pipe inspection system based mobile robot) and several achievements such as, the best poster in SPRINT 2014, one of the 106 Indonesian Innovators by BIC-RISTEK DIKTI in 2014, the best poster in KIPNAS XI in 2015, student travel grant in IEEE APCCAS 2016, and one of 108 Indonesian Innovators by BIC in 2016. His research interests include: Analog circuits design, instrumentation system, Internet of Things, 


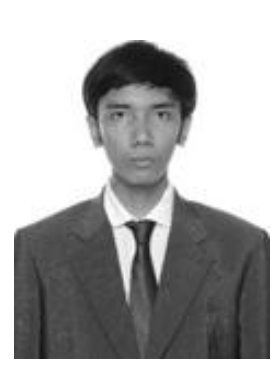

circuit simulation, engineering education, multimedia learning, game conceptor, and optical wireless communication.

Angga Pratama Putra received his B.Sc. degree on Electrical Engineering from Institut Teknologi Bandung (ITB), Indonesia in 2015. He is currently Master Student majoring in Electrical Engineering with specialization in Computer Engineering (M.Cs), also in ITB. His research interests include: Embedded System, Software Engineering, VLSI, System-on-Chip, Internet of Things, Digital Signal Processing (DSP) and Visible Light Communication (VLC).

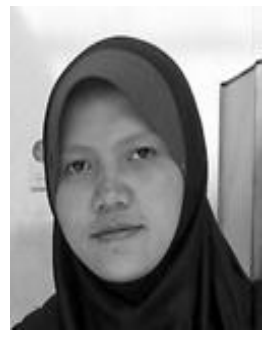

Yulian Aska, received his B.Sc. degree on Electrical Engineering from Institut Teknologi Bandung (ITB), Indonesia in 2014. Now, she is a yunior researcher member in Microelecronic Center ITB (Control system laboratory and IC design laboratory). Her research interests include, control system \& automation, VLSI, System-on-Chip, Digital Signal Processing (DSP) and optical wireless communication.

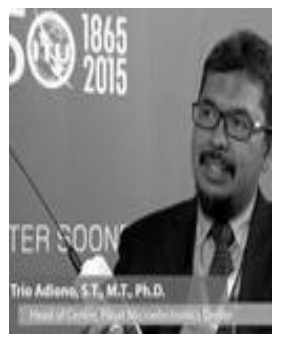

Trio Adiono obtained his Ph.D. degree in VLSI Design from Tokyo Institute of Technology, Japan, in 2002. He received the "Second Japan Intellectual Property Award" in 2000 from Nikkei BP for his research on "Low Bit-rate Video Communication LSI Design". He also holds a Japanese Patent on "High Quality Video Compression System". Currently, he is a lecturer at the School of Electrical Engineering and Informatics, a Head of the Microelectronics Center and IC Design Laboratory, ITB. He currently serves as a chair of the IEEE SSCS Indonesia Chapter. His research interests include VLSI, Signal and Image Processing, Visible Light Communication, Smart Card, Electronics Solution Design and Integration. 